\title{
eLGOSS: A Support System for e-Learning Governance
}

\author{
Lúcia B. Baruque ${ }^{1}$, André L. Brazil ${ }^{2,3}$, Cássia B. Baruque ${ }^{1}$ \\ ${ }^{1}$ Departamento de Mídias Digitais \\ Fundação CECIERJ / Consórcio CEDERJ - Rio de Janeiro, RJ - Brasil \\ ${ }^{2}$ Instituto de Computação - Universidade Federal Fluminense (UFF) \\ Rio de Janeiro, RJ - Brasil \\ ${ }^{3}$ Campus Eng. Paulo de Frontin - Instituto Federal de Educação, Ciência e Tecnologia \\ do Rio de Janeiro (IFRJ) - Rio de Janeiro, RJ - Brasil \\ luciabaruque@yahoo.com.br, abrazil@ic.uff.br, cbaruque@gmail.com
}

\begin{abstract}
LGORM is a reference model for e-Learning Governance which aims at guiding and optimizing e-learning initiatives and developments in institutions. Our Reference Model conceptual framework encompasses an e-learning information architecture, processes and sub-processes, and, governance rules and metrics which were described in a previous work. But a reference model is not enough to ensure elearning governance. Its processes and activities should be supported by information systems to foster efficiency, accuracy and better results. To this end, we have been working on the development of an e-Learning Governance Support System - the eLGOSS. In this work we report on how eLGOSS system can help in the coordination of e-learning activities in order to foster the achievement of better performance results.
\end{abstract}

\section{Introduction}

e-Learning governance can be defined as the responsibilities and practices carried out with a view to providing strategic direction to an institution' e-learning initiatives, ensuring that established objectives are achieved and risks managed properly, as well as that resources allocated are used responsibly [Baruque 2004].

Organizations use different approaches and technologies, as well as models for the delivery of e-learning contents. But how distance learning tasks are being coordinated? What models, methodologies, systems and tools are there to help in governing e-learning activities?

Too much work has been devoted to develop excellent tools and techniques aimed at addressing specific educational and technical needs. However, more attention should be given to guide in the adoption of a comprehensive approach that can integrate all aspects present in the coordination of e-learning activities, such as organizational, administrative, instructional and technological . eLGORM was conceived and developed with this intention. But a reference model is not enough to ensure e-learning governance. The processes and activities called for by this model must be supported by information systems to foster efficiency, accuracy and better results. To this end, we have been working on the development of the eLGOSS system. 
This work specifically focus on how eLGOSS can help in managing the processes, data structures and governance rules and metrics established by eLGORM.

The remainder of this paper is organized as follows. Section 2 presents related work. In Section 3, we show the methodology used to develop the eLGOSS system. Section 4 gives an overview of the eLGORM model to help in understading eLGOSS functions and data, which are described in Section 5. Section 6 presents the results which can be obtained by the use of eLGOSS, in the coordination of WBE activities. Section 7 presents our conclusions and future work.

\section{Related Work}

The term e-Learning governance was first conceived at a doctoral thesis as a major theme for research in 2004 [Baruque 2004]. In this work, a reference model for elearning governance - eLGORM - was proposed and assessed by some corporate and academic representatives. eLGORM is aimed at helping institutions in the adoption and optimization of e-learning processes and activities.

[Marshall and Mitchell 2002] indicates that a process model is needed to the guide the improvement of e-learning. In order to develop such a model, they apply the known Capability Maturity Model or CMM in the domain of e-learning. They present a framework that shows a set of possible outcomes for defining each of the possible levels in a maturity model. Thus, a quality framework for continuous improvement of elearning has been developed, helping in classifying each process capability in a certain maturity level [Marshall 2010]. Similar to this, [Penicina 2011] proposes that e-learning implementation and maintenance business processes be incorporated in the classic PDCA cycle aiming at an organizational e-learning capability maturity model.

Another work related to ours is found in [Anta 2002]. This guide was developed by the Australian National Training Authority (ANTA) to help auditors in reviewing the quality of online materials and verifying the compliance with the Standards for Registered Training Organizations. It has 9 standards: Quality Training and Assessment, Compliance with Commonwealth, State/Territory Legislation and Regulatory Requirements, Effective Administrative and Records Management Procedures, Access and Equity and Client Service, the Competence of the RTO staff, RTO assessments, Learning and Assessment Strategies.

[Allaedine 2010] as well as [Chang \& Uden 2008] propose the main components for an e-learning governance framework with structures, processes, communications and relational mechanisms, and pedagogies and instructional designs. The framework is intended to provide a model or principles for managers to use when evaluating, directing and monitoring the use of elearning in their organizations.

eLGORM, apart from being the first model proposed in the literature to address the issue of e-learning governance, differs from other frameworks given its comprehensiveness. Further to other relevant guidelines, not found in our literature review of other e-learning models, eLGORM contains not only the processes but also the information structures used in the e-learning processes and well as governance rules and metrics to provide guidance in the coordination and optimization of e-learning activities. Section 4 gives an overview of eLGORM and its main components. The 
eLGOSS system, described in Section 5, is under development to support eLGORMrelated functions and activities.

\section{Methodology}

In order to develop eLGORM and eLGOSS, the following steps were taken: (1) defining the characteristics of a reference model; (2) structuring the e-learning function into processes and sub-processes so that governance principles could be applied; (3) adapting the ISDMeLO methodology [Baruque and Melo 2005] for the design of elearning contents in the context of e-learning processes; (4) searching for quality standards for e-learning; (5) assessing possible risks in the e-learning processes; (6) proposing governance rules and metrics for e-learning based on COBIT and COSO and the authors'experience; (7) defining the main e-learning information flows and their attributes to build an information architecture; (8) validating the ELGORM model with representatives of the local and international community from the academic and corporate sectors; (9) carrying out the functional specification of eLGOSS using the UML and data classes diagrams, based on the eLGORM conceptual framework; (10) developing an eLGOSS prototype to allow for visualizing the results which can be obtained by the implementation of the proposed system and (11) establishing how the results obtained by eLGOSS's use can help managers in coordinating, monitoring and improving e-learning activities.

\section{4. eLGORM Model Overview}

A Reference Model is "a framework for understanding significant relationships among the entities of some environment, and for the development of consistent standards or specifications supporting that environment" [HP 2002] [Hollingsworth 1995].

eLGORM aims at defining the concept of e-learning governance and to serve as a guide for organizations that wish to initiate, develop and optimize its e-learning activities and processes. In reality, such model aims at assisting the organization in the establishment of an environment which promotes the individual and organizational learning in line with its strategic objectives and considering the interests and aspirations of all parties involved.

eLGORM encompasses the components presented in Figure 1:

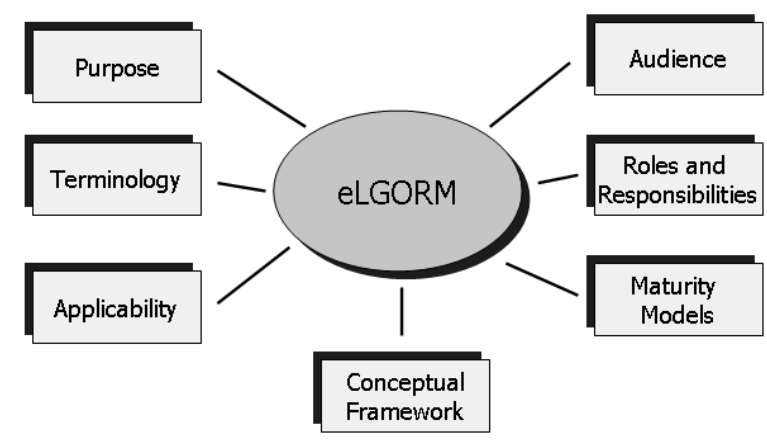

Figure 1 - eLGORM's Components 
eLGORM's conceptual framework is the most important component of the reference model. It proposes e-Learning processes, information structures and governance rules and metrics. See Figure 2.

Based on the Deming Cycle, we structured the e-Learning governance processes into: Corporate e-Learning Program Planning, Corporate e-Learning Program Execution and Optimization of e-Learning processes. In [Baruque et al 2004], we described eLGORM processes in details. [Baruque and Melo 2006] gives a thorough description of eLGORM's governance rules and metrics with some examples. As we stated before, a reference model is not sufficient for e-learning governance activities. They must be supported by an information system for their effectiveness. As such, ELGOSS, which is described in the next section, is aimed to assist in the management of the processes, information structures and metrics proposed by eLGORM.

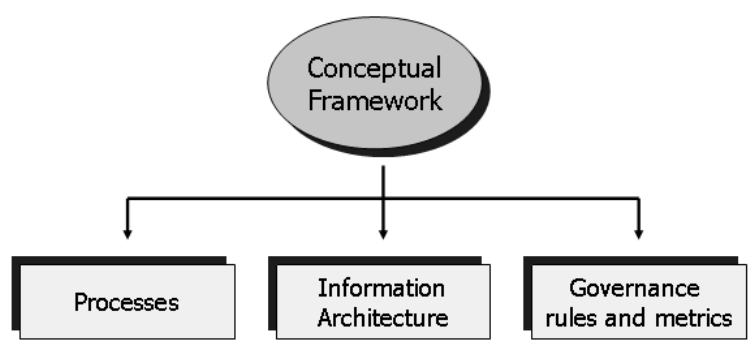

Figure 2 - eLGORM's Conceptual Framework

\section{5. eLGOSS Specification and Implementation}

This section shows the functional specification of eLGOSS using the Unified Modeling Language - UML where we can identify the system's main functions and users. A further description is given on the eLGOSS's use cases together with data classes established for e-learning planning and project monitoring.

\section{1 eLGOSS’s Use Cases}

Figure 3 shows eLGOSS's use cases from the Analysis of the institutional e-learning current situation through the optimization of the institutional e-learning processes, as recommended by eLGORM.

The use of eLGOSS, described in the aboved figure, starts when the Chief Learning Officer, utilizes the Analysing the Current Situation function (Use Case 1) to input information resulting from an institutional analysis on the institution's readiness to adopt or improve e-learning. The information are fundamental for the formulation of elearning strategies and for the planning of the Corporate e-Learning Program.

The function Planning the e-Learning Programa (Use Case 2) supports the elaboration of an institutional e-learning program as well as the annual plan to be implemented with its respective technical and administrative infrastructures. At this step, eLGOSS already allows the storing of the governance rules and metrics.

Once the e-Learning Steering Committe approves the e-learning projects to be carried out during the year, a Project Manager will develop a workplan to each one, 
allocating resources and deadlines to the tasks to be carried out by the team, including, but not limited to, the instructional designers as well technical support staff.

The function Designing e-Learning Modules (Use Case 3) allows storing all administrative and technical information related to the analysis and design phases of elearning modules. Following it, the function Developing e-Learning Modules (Use Case 4) supports the subsequent phases of the instructional design project, capturing information on the specification of e-learning modules' contents, which can be composed by learning objects, and their interface.

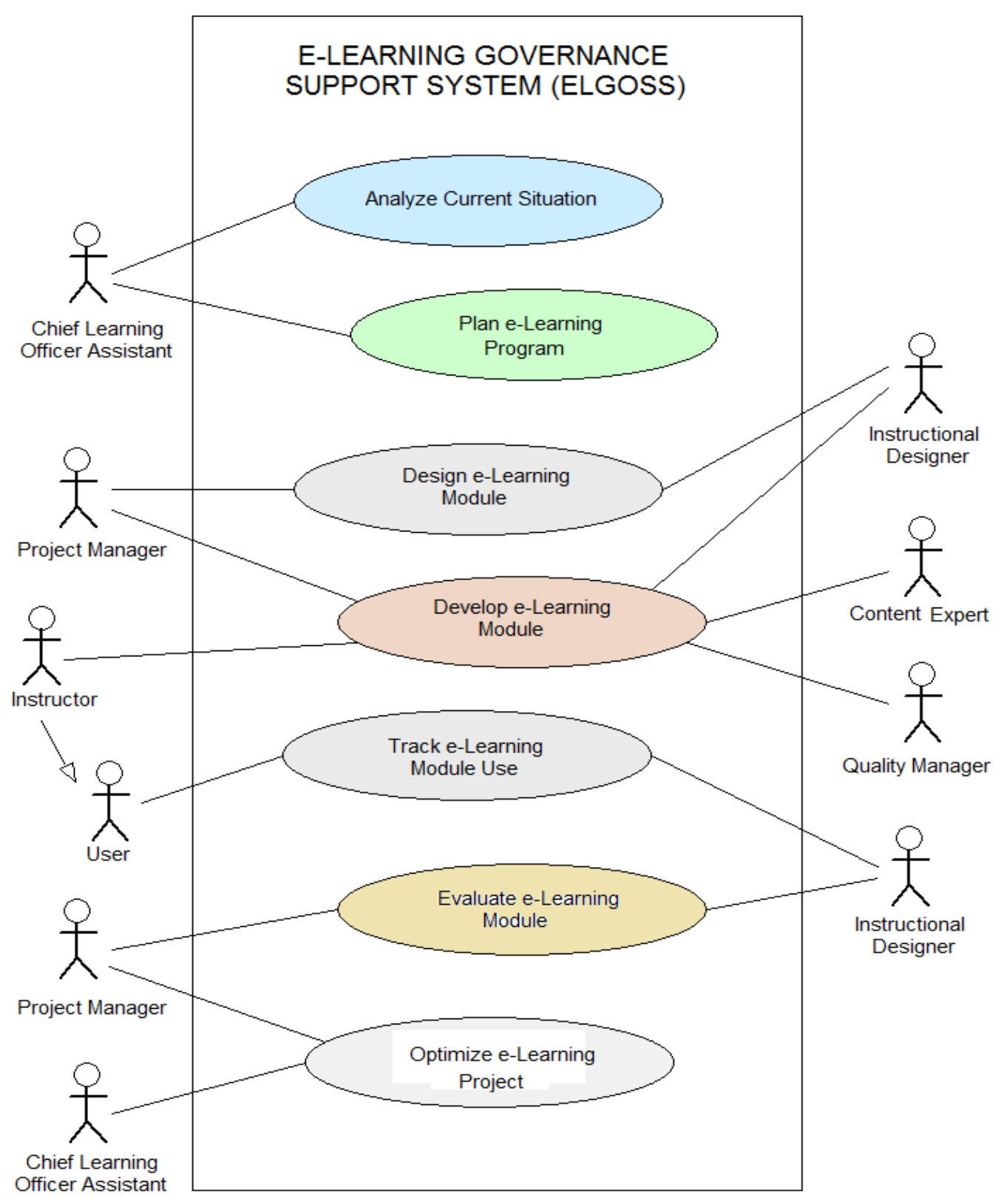

Figure 3 - Elgoss Use Case Diagram 
Information on instruction delivery plans and on the use of the e-learning modules by learners are also stored in the system so that they can be monitored, when needed.

The function Monitoring the use of e-Learning (Use Case 5), through an integration with a learning management system, allows to monitor the use of learning objects by learner for statistical controls.

The function Evaluating e-Learning Module (Use Case 6) will support formative (before the module is available for use) and somative (after the module is available for use) evaluations to verify the adequacy and effectiveness of e-learning modules developed in terms of their learning results and business impacts.

Finally, the function Optimizing e-Learning Processes (Use Case 7) allows the monitoring of the corporate e-learning program effectiveness, as well as the governance rules and metrics by management or by an independent review function, such as auditing. As part of this review, comments may be documented aiming at improving continuously e-learning processes. Naturally, data referring to all functions listed above will be stored in a database, in accordance with the data modeling that has been carried out during the functional specification phase.

\subsection{The ELGOSS’s Data Modeling}

We show in Figure 4 the data modeling for those ELGOSS functions involved with elearning projects planning and monitoring. It will help understand the interfaces/outputs developed so far and presented in Section 6. It should be noted, however, that ELGOSS data modeling encompasses many other data classes which are not being shown for the purpose of this work.

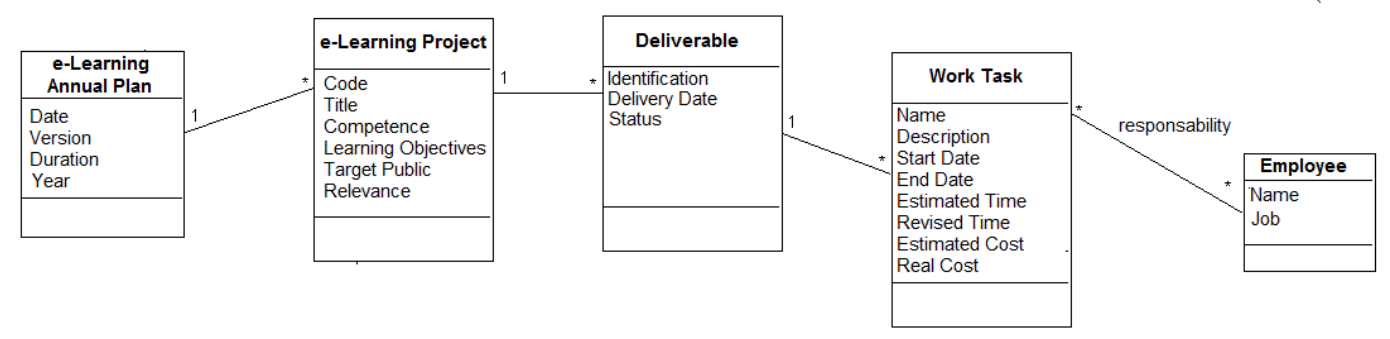

Figure 4 - Elgoss partial Class Diagram

\subsection{Implementation Aspects of eLGOSS}

ELGOSS is being implemented in a web-based environment using the following: The Operation System Linux Ubuntu 12.4 LTS; the Web Server Apache Tomcat 7; the Programming Language PHP and the Database Management System PostgreSQL 9.03.

ELGOSS's prototype, which is under development, focus on the management of the e-learning annual plan and its related projects/deliverables/tasks.

In the next section we will show some system interface/outputs and their relevance for the governance process. 


\section{Results}

As stated before, we need more control over e-learning activities in order to foster results that meet institutional strategic goals. In this initial phase, ELGOSS focus on the modules for controlling the execution of the projects established in the annual e-learning plan called for by the ELGORM model.

We observed that using project management tools, such as the Microsoft Project, does not offer a systemic view of the annual e-learning plan execution. Furthermore, relevant strategic and tactic information are not captured by this tool and therefore does not allow for governing e-learning activities at a tactic and strategic level, as required by eLGORM. For example, since that tool does not allow the aggregation of results of a set of different projects, managers can not have a global view in order to take decisions concerning resources allocation in a more effective way. So, resources reallocation can not be made on a timely manner to foster the achievement of what was established in the annual plan as a whole.

Figure 5 shows ELGOSS interface for the input of tasks which need to be carried out in accordance with the e-learning annual plan. The information are controlled for each e-learning project, which have a number of tasks assigned to different individuals.

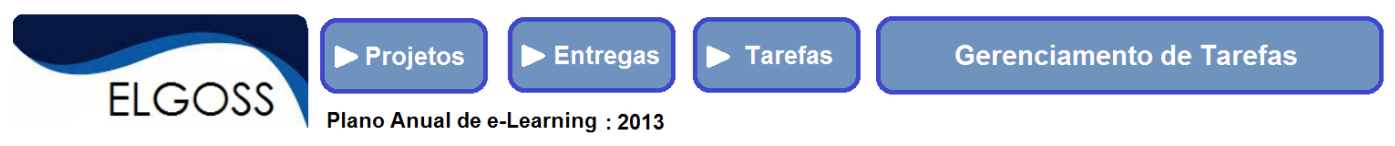

\section{Cadastro de Tarefa}

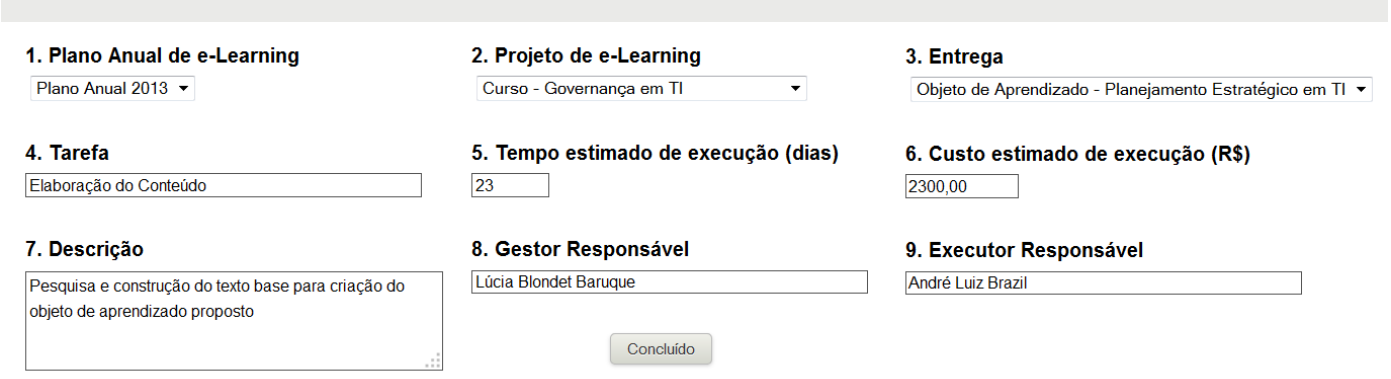

Figure 5 - Elgoss Task Input Interface

It should be noted that once the e-learning annual plan is approved by the steering committee, project managers are assigned to coordinate the activities needed to implement the e-learning projects listed in the annual plan. He or she is responsible for providing the guidelines for each individual project and monitoring its results. Based on this, he or she will report the accomplishments to a higher-level steering committee.

As part of this step, the project manager should elaborate a work plan together with the team, while assigning individual responsibilities and estimated mandays and costs for task completion. Collecting relevant information for the e-learning projects, listing the deliverables and establishing a schedule are part of his/her duties. Based on the established work plan, the team will carry out the tasks needed to develop the elearning modules. The interface shown in Figure 5 allows inputting these data. As stated 
in [Nunes and Schiel 2011], a well done instructional design planning and monitoring will benefit the student's learning.

Monitoring the results of the e-Learning projects is fundamental to help ensure that institutional objectives are achieved and costs and deadlines are met. eLGOSS interface shown in Figures 6 and 7 allows this monitoring with aggregated results. Based on the information provided by the team and his/her observations, the project manager should input information for each e-learning project task that will help in the consolidation of the yearly results and final reporting to the steering committee. The steering committee will evaluate the actual results vis-à-vis the annual plan and make the changes needed. The project priorities may be changed as a result of this process.

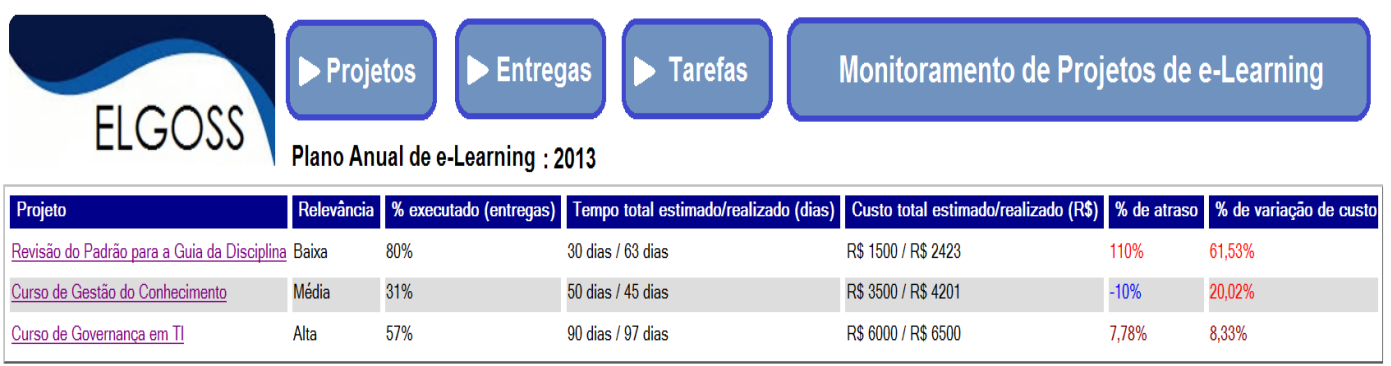

Figure 6: Elgoss E-Learning projects management report

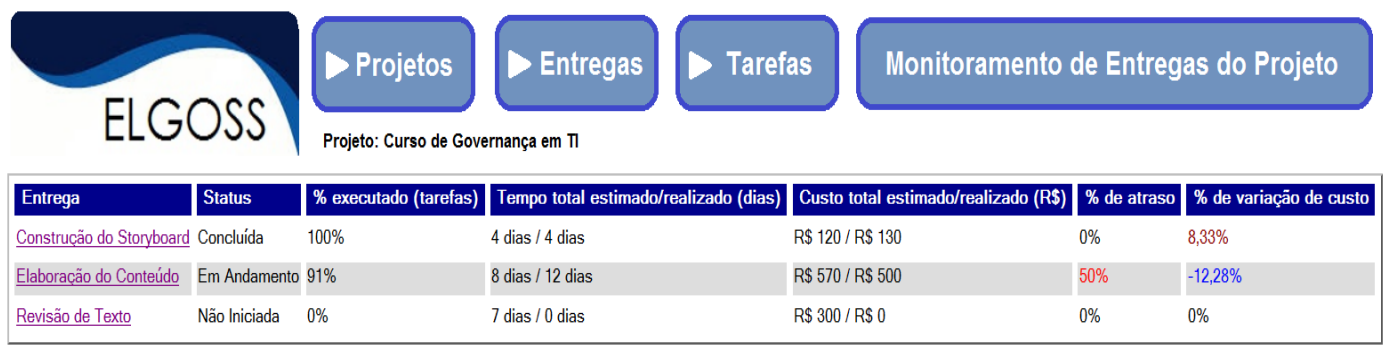

Figure 7: Elgoss e-Learning deliverables management report for the project Curso de Governança em TI

\section{Conclusion and Future Work}

E-learning is a strategic advantage to organizations and governance is needed to ensure success in e-learning implementation and optimization. The literature review has shown that some scholars have focused on establishing e-learning processes benchmarks and capability maturity levels for e-learning continuous improvement. eLGORM is a more comprehensive framework which goes beyond processes and includes information structures and governance rules and metrics as well, beside other relevant information. However, a reference model is not sufficient for e-learning governance activities. They must be supported by an information system for their effectiveness.

In this work, we described a system - eLGOSS - to support eLGORM's related guidelines and activities. In this initial phase, we developed a prototype that focus on the monitoring of e-learning projects implementation. It can help in the management of time and costs allowing a systemic view on the use of e-learning resources and their 
reallocation on a timely manner. As future work, we envisage to continue developing eLGOSS to meet the guidelines established by eLGORM.

\section{References}

BARUQUE L. (2004) eLGORM: e-Learning Governance Reference Model, Doctoral Thesis, Computer Science Department, Pontifícia Universidade Católica do Rio de Janeiro.

MARSHALL S.; MITCHELL. (2002) An e-learning Maturity Model?,University Teaching Development Centre, Victoria University of Wellington GTON, New Zealand; Available at: http://www.ascilite.org.au/conferences/auckland02/ proceedings/papers/173.pdf. Access in: August 2013.

MARSHALL S. (2010) A Quality Framework for Continuous Improvement of Elearning: The E-learning Maturity Model. The Journal of Distance Education. Volume 24, No. 1. Available at: http://www.jofde.ca/index.php/jde/article/view/606. Retrieved in August 2013. Accessed in: August, 2013.

PENICINA L. (2011) Towards e-Learning Capability Maturity Model. Scientific Journal of Riga Technical University. Computer Sciences. Volume 43, Issue -1, Pages 88-91, ISSN (Print) 1407-7493, DOI: 10.2478/v10143-011-0012-7, October 2011.

ANTA. (2002). Australian National Training Authority. Quality Auditing for on-line learning - A guide for AQTF Auditors. The Australian Flexible Learning Framework. 2002 Available at: http://flexiblelearning.net.au/qualityaudit/ qa_guidelines_31october.doc. Accessed in: August, 2013.

CHANG, V. and UDEN, L. (2008) Governance for ELearning Ecosystem. $2^{\text {nd }}$ International Conference on Digital Ecosystems and Technologies (DEST). Available at: eeexplore.ieee.org/xpl/login.jsp?tp=\&arnumber $=4635164 \& u r l=h t t p \% 3 \mathrm{~A} \% 2 \mathrm{~F} \% 2$ Fieeexplore.ieee.org\%2Fxpls\%2Fabs_all.jsp\%3Farnumber\%3D4635164. Accessed in: August, 2013.

ALLAEDINE, M. (2010). ELearning Governance - Towards an Applicable Framework to Make eLearning Decisions Based on COBIT and ISO/IEC 38500. Proceedings of the $5^{\text {th }}$ International Conference on e-Learning. Malaysia. Available at: http://www.academic-conferences.org/pdfs/ICEL_2010-abstract_booklet.pdf.

Accessed in: August, 2013.

HOLLINGSWORTH, D. (1995), Workflow Management Coalition - The Workflow Reference Model, Document no. TC00-1003, Document Status - Issue 1.1. Available at: http://www.wfmc.org/standards/docs/tc003v11.pdf. Accessed in: August, 2013.

HP 2003. Hewllet-Packard Development Company. (2003). "The HP IT Service Management (ITSM) Reference Model". Available at: http://www.hp.com/hps/model/. Accessed in: July, 2013. 
BARUQUE L. and MELO R. (2005). "Learning Theory and Instructional Design using Learning Object"; Journal of Educational Multimedia and Hypermedia. 13(4), 343370. January, 2005

BARUQUE, L. BARUQUE, C. MELO, R. (2007). Towards a Framework for Corporate e-Learning Evaluation. Proceedings of the 2007 Euro American conference on Telematics and information systems. ISBN: 978-1-59593-598-4 doi $>$ 10.1145/1352694.1352754. Available at: http://dl.acm.org/citation.cfm?doid= 1352694.1352754. Accessed in: August, 2013.

BARUQUE, L. and MELO, R. (2006). Reference Model for e-Learning Governance. Proceedings of the 22nd ICDE (International Concil for Open and Distance Education).

NUNES, I and SCHIEL, U. (2011). Design Instrucional e seu acompanhamento em tempo de execução utilizando Rede de Atividades. Anais do XXII SBIE - XVII WIE. Available at: http://www.academia.edu/1370911/Design_Instrucional_e_seu_acompanhamento em tempo de execucao utilizando Rede de Atividades. Accessed in: Augst, 2013. 